\title{
DEVELOPMENT OF A HYDROGEN RESISTANT SUPERALLOY FOR SINGLE CRYSTAL BLADE APPLICATION IN ROCKET ENGINE TURBOPUMPS
}

\author{
P. Caron*, D. Cornu**, T. Khan* and J.M. de Monicault** \\ * Office National d'Études et de Recherches Aérospatiales (ONERA) \\ BP 72 - 92322 Châtillon - France \\ ** Société Européenne de Propulsion (SEP) \\ BP 802 - 27207 Vernon - France
}

\begin{abstract}
A new single crystal Ni-Fe based superalloy, designated THYMO NEL 8, was developed in order to satisfy the specific requirements of rocket engine turbopump airfoils. The principal objective was to obtain an alloy with a high fatigue resistance together with a low susceptibility to hydrogen environment enbrittlement (HEE). The effects of the distribution of strengthening $\gamma^{\prime}$ precipitates on the tensile properties of the alloy were investigated. The best balance between tensile strength and ductility was obtained with a duplex dispersion of $\gamma^{\prime}$ particles. Smooth and notched tensile tests performed at $300 \mathrm{~K}$ showed a susceptibility to HEE significantly lower than that of single crystal superalloys designed for aircraft applications. THYMONEL 8 exhibited improved low cycle fatigue and stress-rupture properties compared to forged Superwaspaloy used by S.E.P. for turbopump rotors. In addition, THYMONEL 8 exhibited higher thermal conductivity and lower Young's modulus than the single crystal alloys for aircraft turbines, which is beneficial for the thermo-mechanical strength.
\end{abstract}

\section{Introduction}

High strength $\gamma / \gamma^{\prime}$ nickel base superalloys are used extensively in turbopump turbines for rocket engines. The operating conditions in hydrogen fueled rocket engines are, in some respects, more severe than for aircraft turbine engines (1). Indeed the turbopumps operate in a gaseous hydrogen environment at high pressure which requires the use of alloys with a low susceptibility to hydrogen environment embrittlement (HEE). Moreover the thermal transients experienced by the rocket engine turbines are more severe than those encountered in aircraft turbines, resulting in harmful low and high cycle fatigue conditions on the blades. On the other hand, the targeted life is only of the order of a few hours and the maximum use temperature is not higher than $1100 \mathrm{~K}$, a further increase of the turbine inlet temperature producing no significant power improvement.

Up to now, two separate approaches have generally been taken to improve the performance of the alloys constituting the turbopump blades : i) to develop specific chemistries of superalloys showing a low susceptibility to HEE (2), (ii) to select existing single crystal superalloys previously designed for aircraft turbine blade applications in order to take advantage of their unique thermo-mechanical strength, both due to the low value of the Young's modulus along the $\langle 001\rangle$ growth direction and the absence of defects such as grain boundaries, carbides or coarse $\gamma^{\prime}$ particles $(1,3)$. However, this latter class of superalloys generally exhibit a substantial or strong susceptibility to HEE that makes them inadequate for applications in hydrogen environment $(1,4)$. Advanced rocket engine technology with improved efficiency and service life therefore relies on the development of specific chemistries for single crystal superalloys showing a high fatigue resistance together with a low susceptibility to HEE (1). This paper describes the approach adopted to define a new superalloy, designated THYMONEL 8, suitable for turbopump blade applications, as well as the results pertaining to the evaluation of its microstructural, physical and mechanical characteristics.

\section{Alloy Development}

The objective was to design an alloy with improved thermo-mechanical properties compared to the forged Superwaspaloy, used in turbine rotor of the turbopump designed by VOLVO from Sweden for the "Vulcain" engine developed by S.E.P., while maintaining a low susceptibility to HEE.

A series of experimental superalloys with compositions based on the Ni-Fe-Cr-Mo-Al-Ti-Nb system were first defined for screening tests. The choice of nickel-iron based alloys was justified by the good balance between strength and resistance to HEE generally exhibited by this class of alloys of which Incoloy 903 is the best example $(5,6)$. Chromium was added for improving the oxidation/corrosion resistance and molybdenum was introduced as a solid solution strengthener of the austenitic alloy matrix. Aluminium, titanium and niobium were added to enhance the precipitation of the strengthening, ordered $\mathrm{L}_{2}-\gamma^{\prime}$ phase $(\mathrm{Ni}, \mathrm{Fe})_{3}(\mathrm{Al}, \mathrm{Ti}, \mathrm{Nb})$. Additional objectives were to obtain an alloy characterized by a large solution heat treatment range and a good castability.

Small-scale laboratory heats of the experimental alloys were melted in a high vacuum induction furnace and then used for casting of $\langle 001\rangle$ single crystal rods by the withdrawal process. In view of the results of microstructural and mechanical evaluations on these materials, the THYMONEL 8 alloy was selected as the one showing the best combination of properties. The nominal chemical composition (wt.\%) of this alloy is reported in Table I.

\section{Experimental Procedures}

Single crystal castings used for extensive evaluation of the THYMONEL 8 superalloy were made from heats produced by vacuum induction melting by Aubert \& Duval. 
Table I Alloy compositions (wt.\%)

\begin{tabular}{lccccccccc}
\hline Element & $\mathrm{Ni}$ & $\mathrm{Fe}$ & $\mathrm{Co}$ & $\mathrm{Cr}$ & $\mathrm{Mo}$ & $\mathrm{Al}$ & $\mathrm{Ti}$ & $\mathrm{Nb}$ & $\mathrm{Ta}$ \\
\hline THYMONEL 8 & Bal. & 25 & - & 8 & 3 & 4 & 4 & 1.5 & - \\
\hline AM1 & Bal. & - & 6.5 & 7.8 & 2 & 5.2 & 1.1 & - & 7.9 \\
\hline AM3 & Bal. & - & 5.5 & 8 & 2.25 & 6 & 2 & - & 3.5 \\
\hline
\end{tabular}

$<001\rangle$ oriented single crystal rods were directionally cast by the withdrawal process, either at O.N.E.R.A. using a seed or at industrial foundries using a selector, in low thermal gradient ( $G \approx 40$ K. $\mathrm{cm}^{-1}$ ) directional solidification furnaces. Single crystal rods of the AM1 and AM3 $<001>$ oriented superalloys designed for aircraft turbine blade applications $(7)$ were cast using the same procedure in order to perform comparative tests. Their chemical compositions are reported in Table I.

Tensile tests performed for determining the effect of the $\gamma / \gamma^{\prime}$ microstructure were conducted in air at room temperature, and in argon at higher temperatures, on $4 \mathrm{~mm}$ diameter cylindrical specimens with an initial strain rate of $1.1 \times 10^{-4} \mathrm{~s}^{-1}$. Additional tensile tests were performed at room temperature both on smooth and notched $\left(\mathrm{K}_{\mathrm{T}}=6.2\right)<001>$ single crystal specimens in gaseous hydrogen at a pressure of $10 \mathrm{MPa}$ and in air under atmospheric pressure.

Fully-reversed total strain controlled low cycle fatigue (L.C.F.) tests were performed in air at $1100 \mathrm{~K}$ with a frequency of $0.33 \mathrm{~Hz}$ on a MTS servo-hydraulic fatigue testing machine and using cylindrical specimens with a diameter of $4.65 \mathrm{~mm}$. Constant load tensile stress-rupture tests were conducted in air at 950 and $1123 \mathrm{~K}$ on 3 mm diameter cylindrical specimens.

The thermal conductivity $\chi$ for single crystal alloy samples was calculated via the following relationship using experimentally determined values of thermal diffusivity $\lambda$, heat capacity $C_{p}$ and density $\rho$ :

$$
\chi(\mathrm{T})=\lambda(\mathrm{T}) \mathrm{C}_{\mathrm{p}}(\mathrm{T}) p(\mathrm{~T})
$$

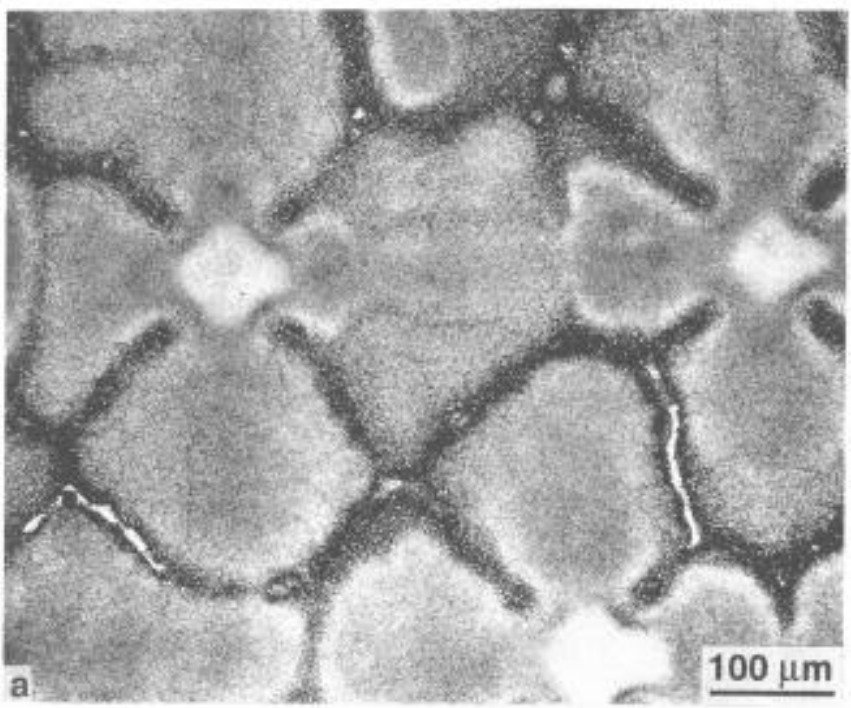

T denotes the temperature at which the relevant properties were determined. Thermal expansion measurements were performed using a ADAMEL DI 24 dilatometer with an argon atmosphere and a heating rate of $0.08 \mathrm{~K} \cdot \mathrm{s}^{-1}$. Heat capacity measurements were made between R.T. and $873 \mathrm{~K}$ using a Perkin Elmer differential scanning calorimeter on small disks $4 \mathrm{~mm}$ diameter and $1 \mathrm{~mm}$ thick. Thermal diffusivity measurements were performed using the laser pulse method on small disks $10 \mathrm{~mm}$ diameter and $3 \mathrm{~mm}$ thick. The faces of the disks were normal to the $<001>$ growing direction of the single crystals. Determination of density was performed at $300 \mathrm{~K}$ using simple volume measurement of a sample of known mass. The densities for temperatures up to $873 \mathrm{~K}$ were calculated from the room temperature values and the measured thermal expansion coefficients at the relevant temperature.

Microstructural observations of $\gamma^{*}$ precipitates and dislocation structures were performed by transmission electron microscopy (T.E.M.) using a Jeol $200 \mathrm{CX}$ microscope operating at $200 \mathrm{KV}$. Thin foils were prepared by electrochemical polishing in a twin-jet Tenupol-3 polisher, using a solution of $45 \%$ acetic acid, $45 \%$ butyl cellosolve and $10 \%$ perchloric acid, cooled to $263 \mathrm{~K}$ and using a potential of $25 \mathrm{~V}$.

\section{Microstructure and Heat Treatments}

The optical micrograph of Figure 1a illustrates the as-cast dendritic microstructure of a THYMONEL $8<001>$ single crystal. A very low amount of $\gamma-\gamma^{\prime}$ eutectic pools was formed in the interdendritic areas.

This alloy has a very large $\gamma^{\prime}$ solution heat treatment window $(\Delta T$

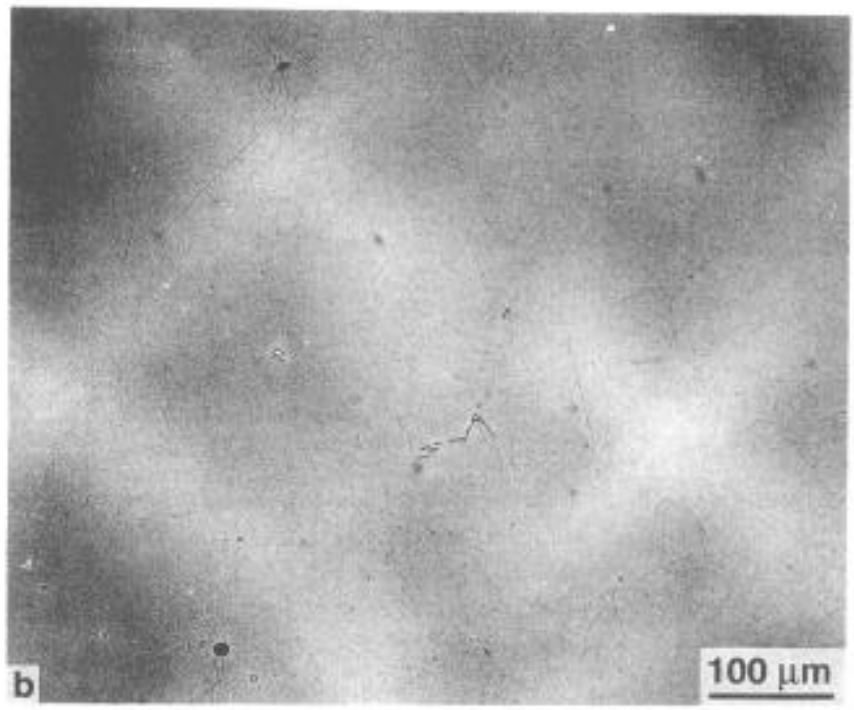

Figure 1: Dendritic microstructure of THYMONEL $8<001>$ single crystal alloy : (a) as-cast, (b) solution heat treated for 3 hours. 

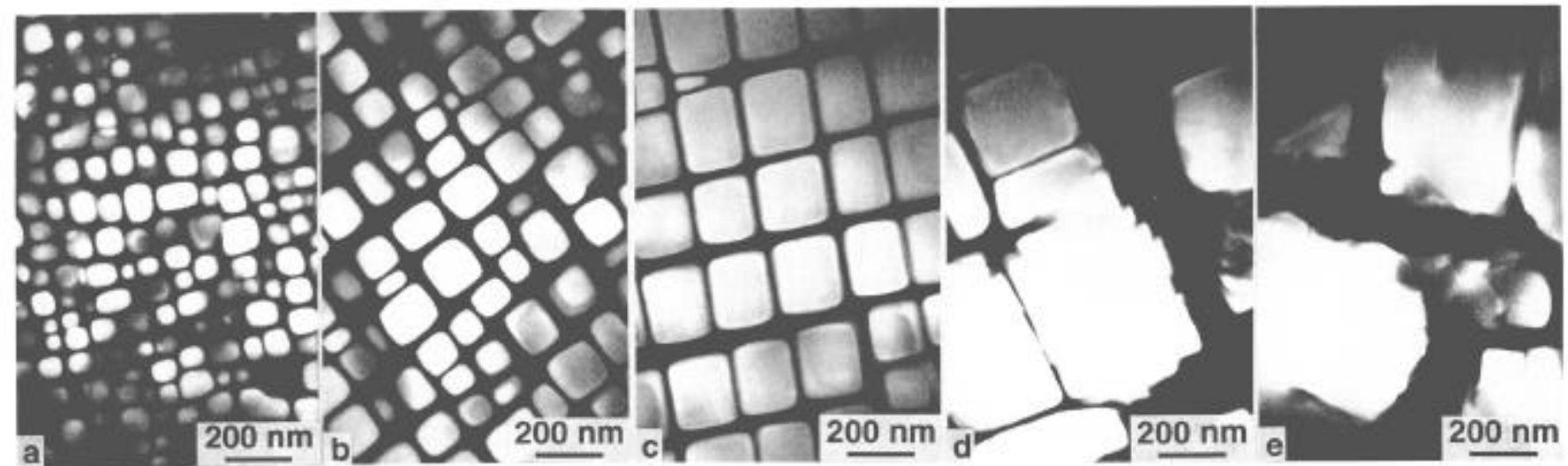

Figure 2: $\gamma^{\prime}$ precipitates in THYMONEL 8 single crystals after ageing procedures applied to achieve a monomodal distribution : (a) heat treatment MA , (b) heat treatment MB, (c) heat treatment MC, (d) heat treatment MD, (e) heat treatment ME (TEM dark field micrographs using $\gamma^{\prime}$ 'diffraction spots).

$=138 \mathrm{~K}$ ) between the $\gamma^{\prime}$ solvus temperature and the solidus temperature. A one-step 3-hour solution heat treatment at a temperature within this window, followed by air cooling, is sufficient to homogenize the dendritic as-cast structure of the single crystals and to solution all the primary and secondary $\gamma^{\prime}$ particles (Figure 1b).

In order to achieve the best balance between tensile strength and ductility, various ageing procedures were applied on homogenized single crystals to produce either monomodal dispersions of $\gamma^{\prime}$ particles with different mean sizes, or duplex dispersions of precipitates with different ratios of small and large particles. Increasing the size of the $\gamma^{\prime}$ particles in single crystal superalloys has been demonstrated to reduce the yield strength but to increase the work hardening rate and the tensile ductility $(8,9)$. These effects result from a transition between the heterogeneous $\gamma^{\prime}$ cutting mechanism by pairs of a/2<110> matrix dislocations and the more homogeneous $\gamma^{\prime}$-bypassing mechanism operating through a combination of slip and climb of $\gamma$ matrix dislocations. On the other hand, a duplex ageing leads to a dispersion of large $\gamma$ ' particles, which renders slip more homogeneous, and a finer dispersion of $\gamma^{\prime}$ precipita-

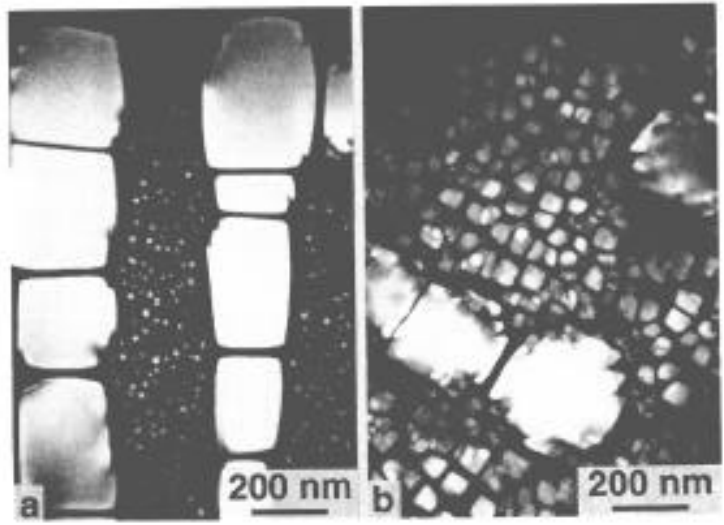

Figure 3: $\gamma^{\prime}$ precipitates in THYMONEL 8 single crystals after ageing procedures applied to achieve a duplex dispersion : (a) heat treatment DA, (b) heat treatment DB (T.E.M. dark field micrographs using $\gamma^{\prime}$ diffraction spots). tes which confers a high yield strength to the alloy (10).

Monomodal $\gamma^{\prime}$ distributions were obtained in THYMONEL 8 using a primary ageing treatment below the $\gamma^{\prime}$ solvus temperature to achieve the desired size of $\gamma^{\prime}$ precipitates. The single crystals were then slowly cooled to a lower temperature and held during a few hours at this temperature, before cooling in air to ambient temperature. The typical $\gamma^{\prime} \gamma^{\prime}$ microstructures obtained using this procedure are illustrated in Figure 2. The mean size of the $\gamma^{\prime}$ particles increased from $70 \mathrm{~nm}$ to $650 \mathrm{~nm}$ when the temperature of the primary ageing increased, while their shape changed continuously from spheroidal to cuboidal, and finally less regular cubes. With primary ageing at the highest temperatures (heat treatments MD and ME), hyperfine precipitates were however observed between the coarser $\gamma^{\prime}$ particles. This secondary precipitation occured, presumably during cooling, in the largest $\gamma$ matrix regions separating coarse $\gamma^{\prime}$ precipitates formed during the high temperature ageing.

Two different duplex dispersions of $\gamma^{\prime}$ phase were produced in THYMONEL 8 using primary ageing treatments at a temperature below the $\gamma^{\prime}$ solvus temperature and secondary ageing treatments at a lower temperature, both followed by air cooling. The resulting $\gamma^{\prime} \gamma^{\prime}$ ' microstructures are illustrated by the T.E.M. micrographs of Figure 3. The fraction of coarse $\gamma^{\prime}$ precipitates is higher with a lower primary ageing temperature. The respective mean size values for the coarse and fine precipitates are 315 and $15 \mathrm{~nm}$ for the heat treatment DA, while they are 430 and $60 \mathrm{~nm}$ for the heat treatment DB where the primary ageing temperature is higher. The heat treatment procedures are coded $\mathrm{MX}$ and DX, where $\mathrm{M}$ or D stand for monomodal or duplex dispersions of $\gamma^{\prime}$ precipitates.

\section{Physical Properties}

The density of THYMONEL 8 was measured to be $7.77 \mathrm{~g} . \mathrm{cm}^{-3}$ that is significantly lower than the typical values for high-strength single crystal superalloys used today for aircraft applications which are close to $8.6-8.7 \mathrm{~g} . \mathrm{cm}^{-3}$.

Figure 4 illustrates the variation with temperature of the thermal conductivity of THYMONEL 8 up to $873 \mathrm{~K}$ compared with the values determined by the same procedure for AM1, a typical high 


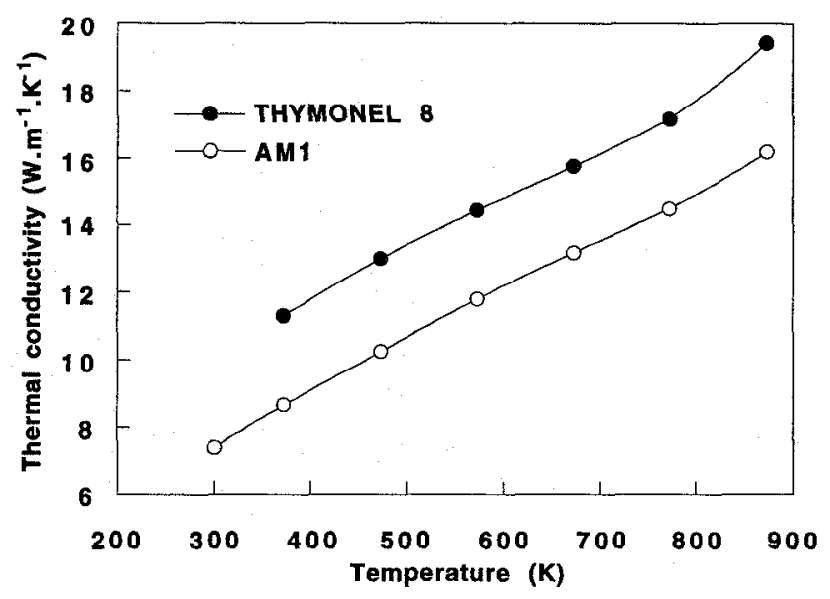

Figure 4: Thermal conductivity of single crystal superalloys THYMONEL 8 and AM1.

creep strength superalloy for single crystal aircraft turbine blades (7). The thermal conductivity of THYMONEL 8 is significantly higher than for AM1 in the whole tempcrature range.

Static Young's modulus measurements were performed between room temperature and $1123 \mathrm{~K}$ on $<001\rangle,<111>$ and $<011>$ THYMONEL 8 single crystals using longitudinal extensometry on tensile specimens deformed in the elastic strain range. The values of the Young's modulus are compared in Figure 5 to those reported elsewhere for AM1 (11). The Young's modulus of these single crystal materials is highly anisotropic, the lowest values being measured along $<001>$ directions, while the highest ones are obtained along $<111>$ directions.

The value of the Young's modulus along the $<001>$ growth direction of the blade is of prime importance because it directly influences the level of stress induced in it due to the thermo-mechanical strain. It is worth noting that the values of the Young's modulus are systematically lower for THYMONEL 8 , which would result in an improvement of the thermo-mechanical strength of the single crystal blade.

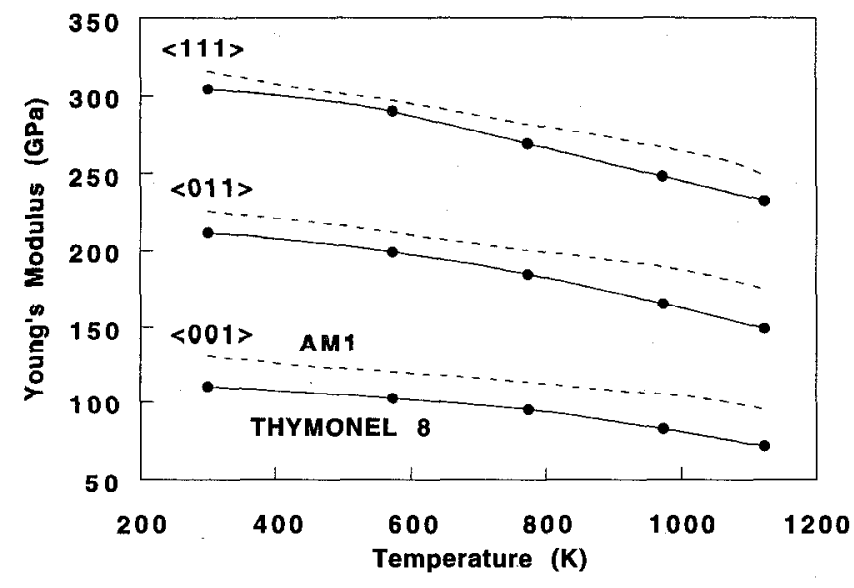

Figure 5: Young's modulus of single crystal superalloys THYMONEL 8 and AM1 along $\langle 001\rangle,<011>$ and $<111\rangle$.

\section{Mcchanical Properties}

\section{Effect of the $\gamma / \gamma^{\prime}$ Microstructure on the Tensile Properties}

Tensile tests were performed between 300 and $1123 \mathrm{~K}$ on $<001>$ THYMONEL 8 single crystal specimens with the different $\gamma / \gamma$ ' microstructures described previously. For the sake of clarity, only the most important and significant results are presented here. Figure 6 illustrates the wide range of values obtained for the $0.2 \%$ yield strength, the ultimate tensile strength and the elongation to rupture by applying the various ageing heat treatments.

The highest yield strength was obtained, in the whole temperature range, with the monomodal distribution of $\gamma^{\prime}$ precipitates exhibiting the finest mean size, i.e. $70 \mathrm{~nm}$ (heat treatment MA). The yield strength increased from 1250 to $1360 \mathrm{MPa}$ between 300 and $873 \mathrm{~K}$, then decreased to about $560 \mathrm{MPa}$ when the temperature increased to $1123 \mathrm{~K}$. However, in these conditions, the ductility was the lowest obtained in the whole temperature range, with a minimum observed at $873 \mathrm{~K}$.

As expected, increasing the $\gamma^{\prime}$ size by increasing primary ageing tempcratures strongly reduced the yicld strength of THYMONEL 8 , the lowest values being obtained with the largest $\gamma^{\prime}$ particles. However, the ductility of the alloy was improved significantly only by using the heat treatment ME. In this case, the ductility minimum shifted to $773 \mathrm{~K}$ with a value of $6.2 \%$. Increasing the $\gamma$ ' precipitate size also led to an increase of the work hardening rate.

The best balance between strength and ductility was however obtained with the ageing procedures producing duplex dispersions of precipitates. Indeed, at $873 \mathrm{~K}$, the yield strength of the alloy with the ageing heat treatment DB attained $1220 \mathrm{MPa}$ with an elongation to rupture of $3.4 \%$ which represents a better compromise between strength and ductility than the alloy containing a fine dispersion of $70 \mathrm{~nm}$ precipitates. At 973 and $1123 \mathrm{~K}$, the yield strengths obtained with the two types of microstructures are comparable.

As for the yield strength, the highest ultimate tensile strength between 300 and $873 \mathrm{~K}$ was obtained with the heat treatment MA producing $70 \mathrm{~nm}$ precipitates. In the case of monomodal distributions of precipitates, increasing the mean size of the $\gamma^{\prime}$ particles decreased the U.T.S., but to a less extent than for the yield strength which is indicative of a higher strain hardening rate. The single crystals with duplex $\gamma^{\prime}$ distributions exhibited comparable values for the U.T.S., irrespective of the temperature of the first ageing heat treatment. At 973 and $1123 \mathrm{~K}$, all types of $\gamma^{\prime}$ distributions produced comparable values of ultimate tensile strength, except for the largest precipitates obtained with the heat treatment ME which gave lower values.

T.E.M. micrographs of Figure 7 illustrate the dislocation structures observed in THYMONEL 8 single crystal specimens, with a monomodal dispersion of $70 \mathrm{~nm}$ precipitates (heat treatment MA) and with a duplex dispersion of $\gamma^{\prime}$ particles (heat treatment $D B$ ), tensile strained up to $2 \%$ at room temperature. In the former case, the deformation is very heterogeneous with high densities of dislocations concentrated in narrow bands. The presence of paired $1 / 2<011>$ dislocations getting away from these dislocation bands is an indication of $\gamma^{\prime}$ precipitate shearing by $<011>$ superdislocations. In the duplex $\gamma^{\prime}$ microstructure, the deformation is still heterogeneous, but the presence of the larger precipitates tend to homogenize the deformation in their vicinity. Straight $<011>$ super- 


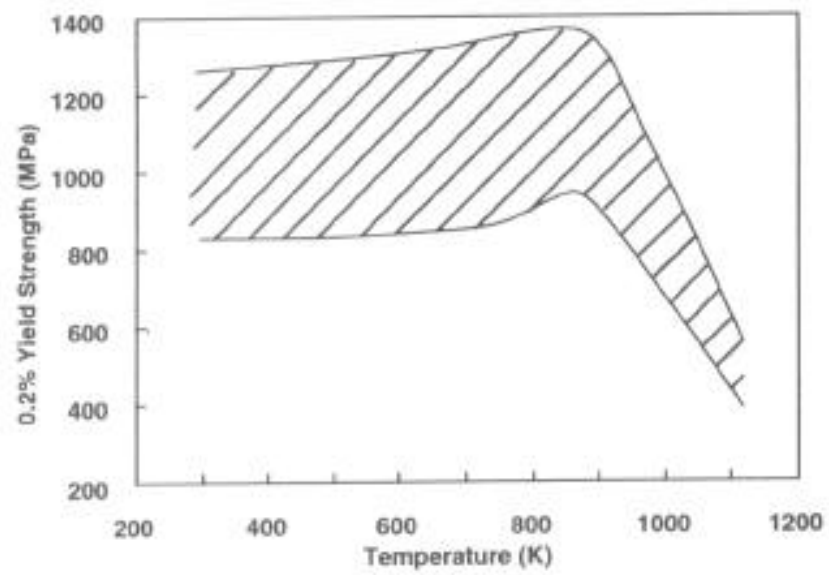

(a)

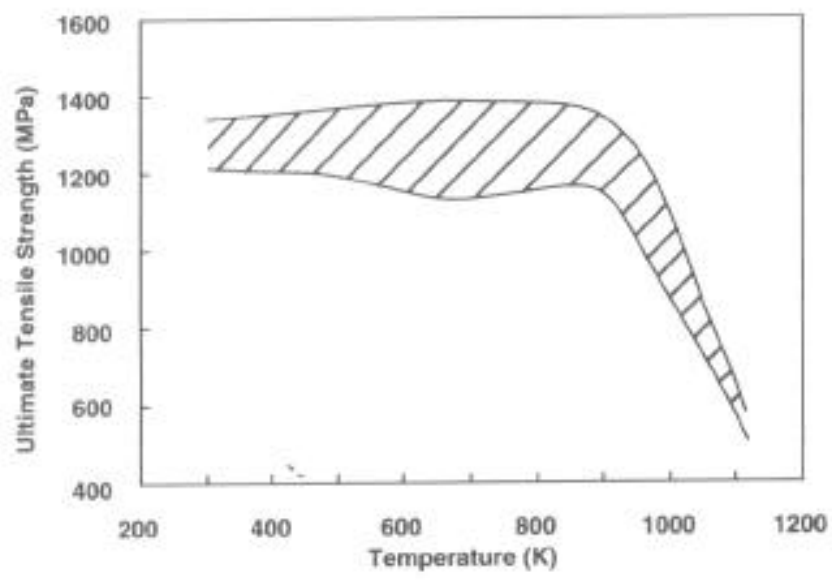

(b)

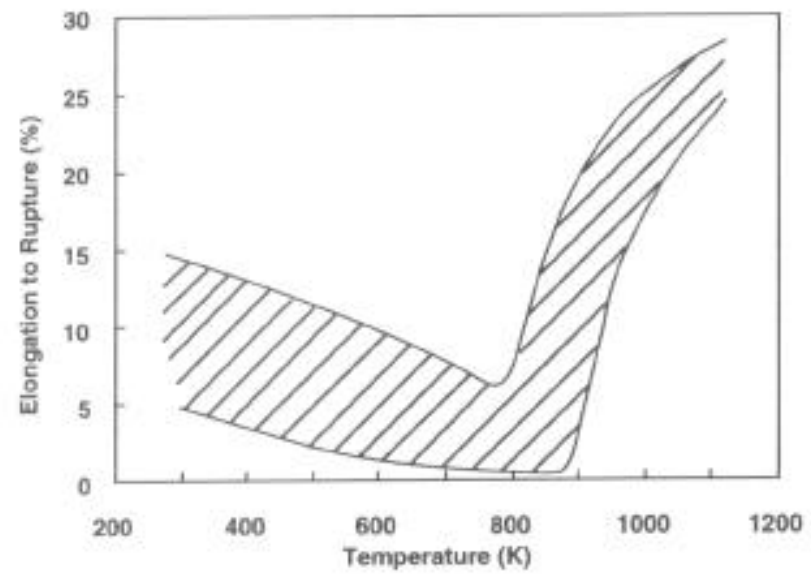

(c)

Figure 6 -Variation with temperature of tensile properties of $<001>$ THYMONEL 8 single crystals with ageing heat treatment procedures producing either monomodal or duplex $\gamma^{\prime}$ precipitate dispersions: (a) yield strength, (b) ultimate tensile strength and (c) elongation to rupture.

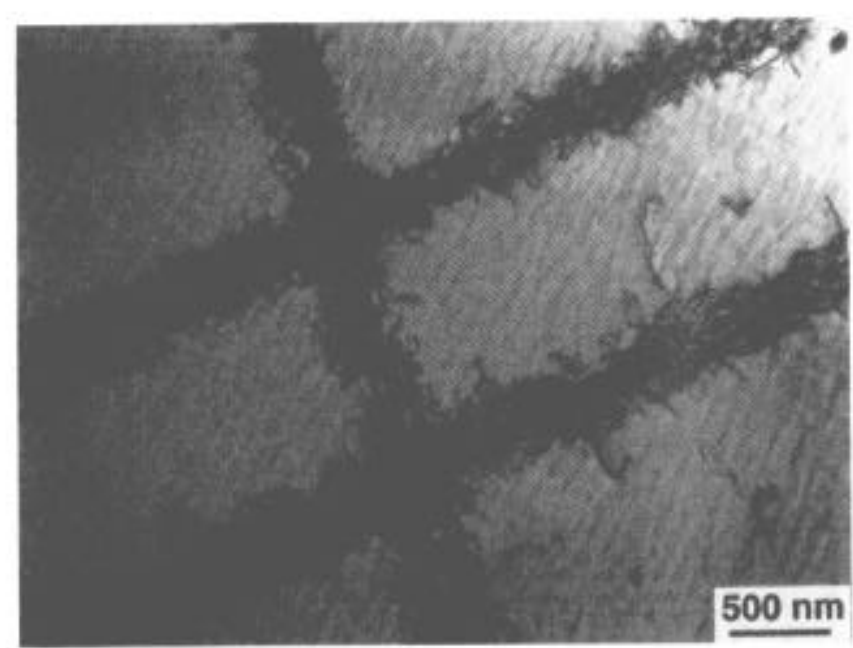

(a)

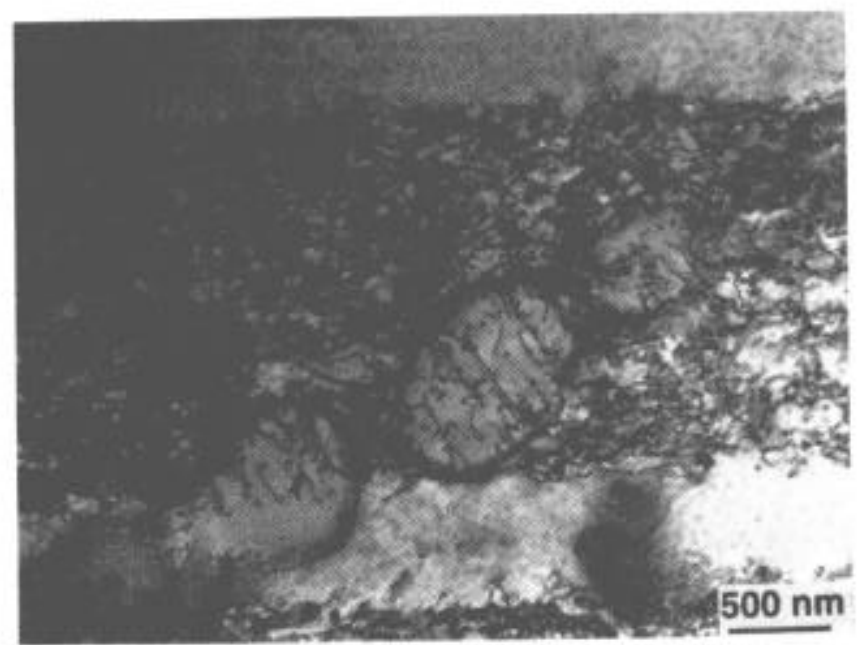

(b)

Figure 7 - Dislocation structures in THYMONEL $8<001>$ single crystals tensile strained to $2 \%$ in air at $300 \mathrm{~K}$ : (a) monomodal dispersion of $70 \mathrm{~nm} \gamma^{\prime}$ precipitates (MA), (b) duplex dispersion of $\gamma^{\prime}$ particles (DB).

dislocations were observed within the coarser precipitates indicating shearing of these $\gamma^{\prime}$ particles.

These results therefore confirm the benefits of a duplex dispersion of precipitates for achieving a balance of tensile properties of the THYMONEL 8 single crystal superalloy. Consequently, the selected heat treatment procedure DB was considered as optimum for the THYMONEL 8 alloy.

\section{Smooth and Notched Tensile Properties in Hydrogen}

Additional tensile tests in air and in hydrogen were performed at $300 \mathrm{~K}$ both on smooth and notched THYMONEL $8<001>$ single crystal specimens with the monomodal dispersion of $70 \mathrm{~nm}$ precipitates (heat treatment MA) and with the optimized $\gamma^{\prime}$ duplex microstructure (heat treatment DB). 
Table II Smooth tensile properties at $300 \mathrm{~K}$ in air and in hydrogen of THYMONEL $8<001>$ single crystals with monomodal dispersion of $70 \mathrm{~nm} \gamma^{\prime}$ precipitates (MA) and duplex dispersion of $\gamma^{\prime}$ precipitates (DB).

\begin{tabular}{|c|c|c|c|c|c|c|}
\hline \multirow[b]{2}{*}{ Heat treatment } & \multicolumn{3}{|c|}{ Air / atmospheric pressure } & \multicolumn{3}{|c|}{$\mathrm{H}_{2} / \mathrm{P}=10 \mathrm{MPa}$} \\
\hline & $\begin{array}{c}0.2 \% \text { Y.S. } \\
(\mathrm{MPa})\end{array}$ & $\begin{array}{l}\text { U.T.S. } \\
\text { (MPa) }\end{array}$ & $\begin{array}{l}\text { Elongation to } \\
\text { rupture }(\%)\end{array}$ & $\begin{array}{c}0.2 \% \text { Y.S. } \\
(\mathrm{MPa})\end{array}$ & $\begin{array}{l}\text { U.T.S. } \\
\text { (MPa) }\end{array}$ & $\begin{array}{l}\text { Elongation to } \\
\text { rupture }(\%)\end{array}$ \\
\hline MA & 1250 & 1320 & 5.4 & 1182 & 1249 & 5.4 \\
\hline$"$ & 1211 & 1271 & 5.1 & 1239 & 1293 & 4.7 \\
\hline DB & 1072 & 1156 & 8.0 & 1115 & 1195 & 7.0 \\
\hline & & & & 1090 & 1135 & 8.0 \\
\hline
\end{tabular}

There was no significant difference between the smooth tensile properties obtained in hydrogen and in air, for both ageing treatments (Table II). The presence of gaseous hydrogen generally does not affect the yield strength of superalloys, which was confirmed by our results. Hydrogen environment generally affects the ductility and, hence, the ultimate tensile strength. In the case of THYMONEL 8, the room temperature ductility was not affected by the presence of gaseous hydrogen independent of the microstructure, which indicated no or low susceptibility to HEE. It has been previously reported that smooth tensile tests performed in hydrogen on single crystals of various superalloys for aircraft turbine blades such as CMSX-2, CMSX-4, René N4 and PWA 1480 show a significant decrease of the UTS compared to tests conducted in air or helium, which was indicative of a loss a ductility (4).

A stronger indication of the susceptibility to HEE is generally given by the ratio of the notched strength in hydrogen to that in air, $\mathrm{R}_{\mathrm{H}_{2}} / \mathrm{R}_{\mathrm{Air}}$. Comparative notched tensile tests were also conducted on AM1 and AM3 (10) <001> single crystals. The respective mean values of the notched tensile strength in air, $\mathrm{R}_{\text {Air }}$; and in hydrogen, $\mathrm{R}_{\mathrm{H} 2}$, together with the values of the ratio $\mathrm{R}_{\mathrm{H}_{2}} / \mathrm{R}_{\mathrm{Air}}$ for the three alloys are compared in Table III. The ratios for THYMONEL 8 with monomodal and duplex dispersions of precipitates were 0.91 and 0.81 which are much higher than the values measured for AM1 and AM3, i.e. respectively 0.46 and 0.54 . The notched tensile strength in air of THYMONEL 8 with a duplex $\gamma$ ' dispersion is very high and comparable to that of AM1 and AM3. The presence of hydrogen reduced the notched tensile strength to a level comparable to that measured in air for THYMONEL 8 with a monomodal $\gamma^{\prime}$ dispersion. It should be noted that the notched strength of THYMONEL 8 with optimized microstructure is higher than its ultimate smooth tensile strength regardless of the environment, whereas it is not the case for THYMONEL 8 with 70 $\mathrm{nm} \gamma^{\prime}$ precipitates. This behaviour results from the higher strain hardening rate observed with the duplex $\gamma^{\prime}$ dispersion.

\section{Low Cycle Fatigue Properties}

Low cycle fatigue test results obtained at $1100 \mathrm{~K}$ on $<001>$ single crystal smooth specimens of THYMONEL 8 containing $70 \mathrm{~nm} \gamma^{\prime}$ precipitates (heat treatment MA) or with the optimized duplex microstructure (heat treatment DB) are compared in Figure 8 with strain controlled $(\mathrm{R}=-1)$ L.C.F. data obtained on forged Superwaspaloy tested at $1023 \mathrm{~K}$ with a frequency of $1 \mathrm{~Hz}$ (12). These results showed no significant effect of the $\gamma / \gamma^{\prime}$ microstructure on the L.C.F. strength of THYMONEL 8. Failures initiated primarily at the surface of the specimen from cracks formed within the external oxide scale (Figure 9a) and sometimes at pores located beneath the surface (Figure $9 \mathrm{~b}$ ). Shorter lives were generally observed when the failure initiated at pores.

Despite the higher testing temperature and the lower frequency, THYMONEL 8 exhibited a dramatic improvement in L.C.F. strength compared to Superwaspaloy. The single crystal superalloy showed a 50X life advantage over Superwaspaloy in the whole strain range.

\section{Stress-Rupture Strength}

Although the creep strength is not a critical property for turbopump applications, some stress-rupture tests were performed between 950 and $1123 \mathrm{~K}$ in air on <001> THYMONEL 8 single crystal specimens in order to establish a comparison with the Superwaspaloy. The alloy was rested both with the monomodal dispersion of precipitates providing the maximum strength and with the optimized $\gamma^{\prime}$ duplex microstructure. The times to rupture covered the range 1-1000 hours under stresses in the range $200-800 \mathrm{MPa}$.

The rupture lives are compared in a Larson-Miller plot (Figure 10) to data published on forged Superwaspaloy (13). The creep strength of THYMONEL 8 is much superior to that of the reference polycristalline alloy Superwaspaloy, particularly at high temperatures. As an example, the rupture life at $1123 \mathrm{~K}$ and $400 \mathrm{MPa}$ in-

Table III - Notched tensile strength $\left(\mathrm{K}_{\mathrm{T}}=6.2\right)$ at $300 \mathrm{~K}$ in air and in hydrogen of $<001>$ single crystal superalloys.

\begin{tabular}{lccc}
\hline & Notched strength (MPa) & Notched ratio \\
\hline Alloy & $\mathrm{R}_{\text {Air }}$ & $\mathrm{R}_{\mathrm{H}_{2}}$ & $\mathrm{R}_{\mathrm{H}_{2}} / \mathbf{R}_{\text {Air }}$ \\
\hline THYMONEL 8 heat treatment MA & 1266 & 1157 & 0.91 \\
\hline THYMONEL 8 heat treatment DB & 1580 & 1278 & 0.81 \\
\hline AM1 & 1638 & 756 & 0.46 \\
\hline AM3 & 1580 & 850 & 0.54 \\
\hline
\end{tabular}




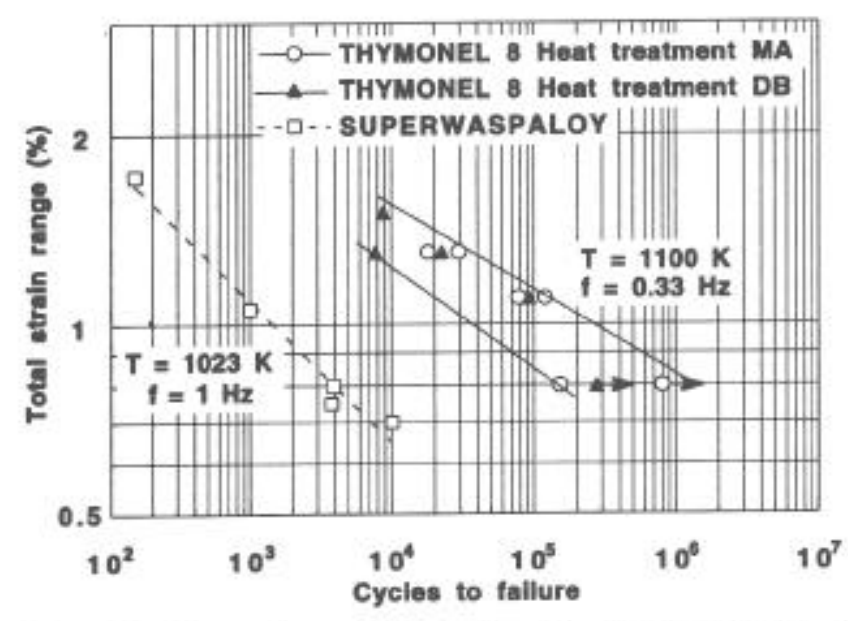

Figure 8 - Comparison of L.C.F. strengths of THYMONEL 8 $<001>$ single crystals and forged Superwaspaloy (12).

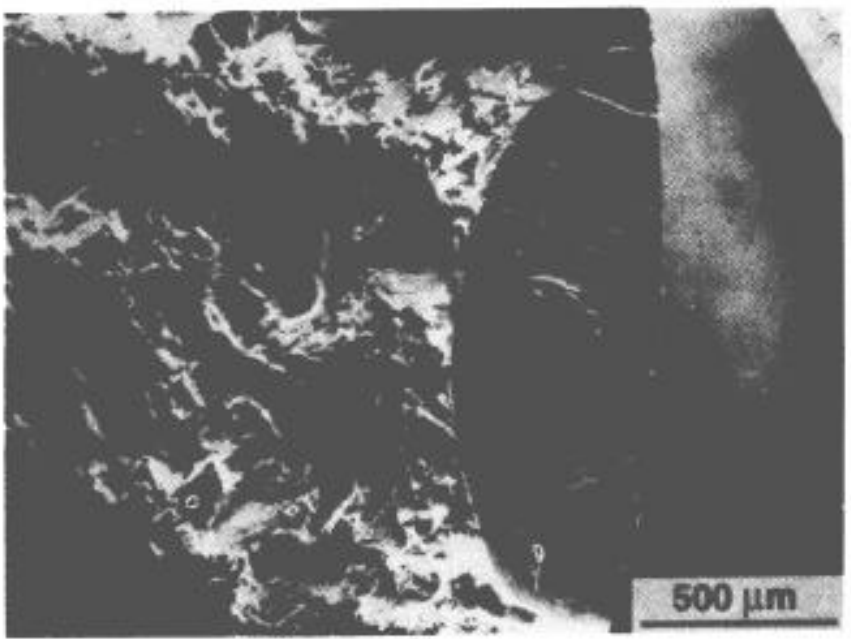

(a)

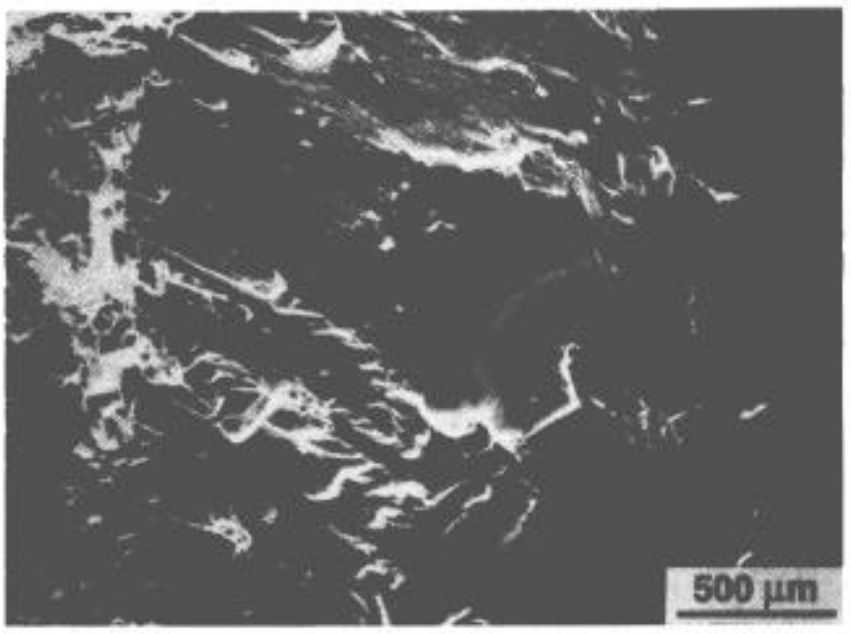

(b)

Figure 9 - SEM micrographs of L.C.F. fracture surfaces of THYMONEL 8 single crystals tested at $1100 \mathrm{~K}$; (a) failure initiation at the specimen surface; (b) failure initiation at pores beneath the surface.

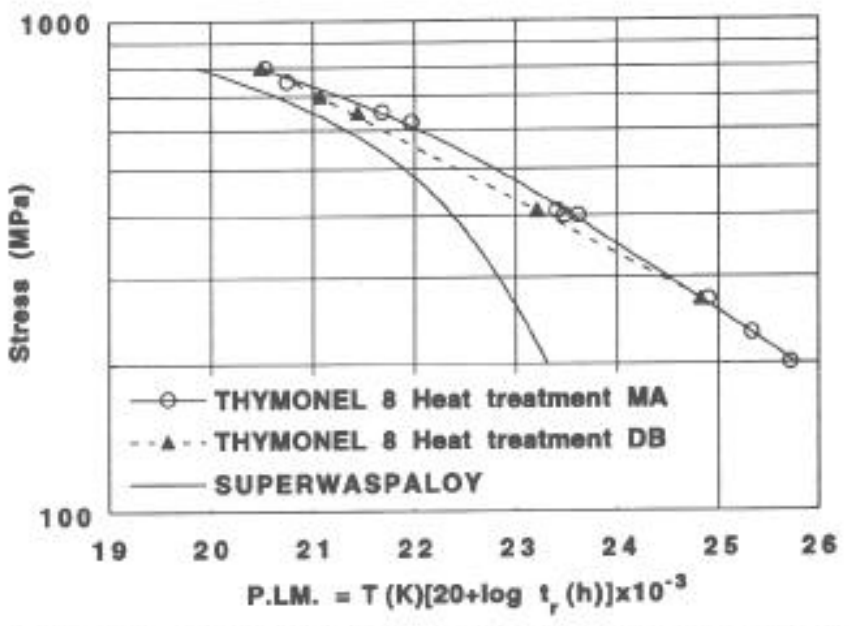

Figure 10 - Larson-Miller plot for stress-rupture lives of THYMONEL 8 and forged Superwaspaloy (13).

creased from 1 to 8 hours when comparing Superwaspaloy with THYMONEL 8.

\section{Discussion of the Results}

The smooth tensile behaviour of the THYMONEL 8 single crystal superalloy has been shown to be very sensitive to the distribution of the $\gamma^{\prime}$ precipitates which contribute to the strengthening of the alloy. The yield strength potential of the alloy is very high as demonstrated in the case of a monomodal dispersion of $70 \mathrm{~nm}$ sized precipitates. However, with this microstructure, the alloy suffered from a lack of ductility, especially in the temperature range 673$873 \mathrm{~K}$. Attempts have therefore been made to improve the ductility of the THYMONEL 8 single crystal alloy, without significantly decreasing its tensile strength, by modifying the $\gamma \gamma \gamma^{\text {' microstruc- }}$ ture using various ageing procedures. In accordance with the results previously obtained on Incoloy 901 (10), the duplex dispersion of $\gamma^{\prime}$ precipitates in THYMONEL 8 confered to the alloy optimum properties in terms of strength and ductility, presumably because of a better homogeneity of the deformation process. The other approach for achieving a homogeneous deformation was to increase the size of the precipitates, while keeping a fairly monomodal dispersion of these particles. This procedure was successful in increasing the ductility of the single crystal, but too detrimental to the yield strength of the alloy, and it was therefore not retained for further evaluation. Moreover, the choice of a duplex $\gamma$ ' microstructure, instead of a monomodal dispersion of small $\gamma^{\prime}$ particles, led to a significant increase of the notched strength of THYMONEL 8 single crystals, both in air and in hydrogen, which is particularly advantageous while considering the residual life of airfoils containing cracks induced by thermo-mechanical stresses.

The susceptibility to HEE of the THYMONEL 8 alloy was investigated by means of both smooth and notched tensile tests at room temperature, and compared to that of competitive single crystal superalloys specifically designed for aircraft turbine blade applications. These tests revealed hardly any susceptibility to HEE for THYMONEL 8, irrespective of the choice of the ageing procedure. The reasons for this excellent behaviour are not really known, but the most important result is that the susceptibility of THYMONEL 8 to HEE is dramatically lower than that of the single crystal 
superalloys previously evaluated for use in turbopump airfoil applications.

The comparison between the L.C.F. strength of THYMONEL 8 single crystals and forged Superwaspaloy confirmed the expected advantage resulting from the low Young's modulus along the $<001>$ growth orientation of the single crystals, together with the absence of defects such as massive primary $\gamma^{\prime}$, grain boundaries or carbides, likely to initiate failure under cyclic deformation. During L.C.F. testing of THYMONEL 8, failure was sometimes initiated on pores, which tends to reduce the life compared to the cases where the failure was initiated at the surface from cracks formed within the oxide scale. A further improvement of the LC.F. behaviour of THYMONEL 8 is possible by using hot isostatic pressing which closes the casting porosity, as previously demonstrated on other single crystal superalloys $(3,14)$. Moreover, some thermomechanical fatigue tests were also performed on hollow $<001>$ single crystal specimens of THYMONEL 8 with duplex $\gamma$ ' precipitation (15). As expected, considering the excellent L.C.F. behaviour of this singlc crystal alloy, together with its rather low Young's modulus and high thermal conductivity, these tests have demonstrated a considerable superiority of THYMONEL 8 over the Superwaspaloy.

\section{Conclusions}

The combination of the various pertinent physical and mechanical properties (low density, high thermal conductivity, low susceptibility to HEE, high tensile strength, low Young's modulus and excellent low cycle fatigue resistance) of the single crystal superalloy THYMONEL 8 makes this material a very suitable candidate for turbompump blades of advanced rocket engines. An other interesting characteristic of THYMONEL 8 is its good creep strength compared to polycristalline superalloys, which makes this alloy a strong candidate for use in future reusable rocket engines. The future work on this alloy will be directed towards the scaling-up and industrial aspects as well as to the more complete understanding of its mechanical behaviour in air and in hydrogen.

\section{Acknowledgments}

A part of this work was supported by the C.N.E.S. The authors acknowledge Mr. J.L. Raffestin (O.N.E.R.A.) for casting of single crystal superalloys.

\section{References}

1. R.L. Dreshfield, and R.A. Parr, "Application of Single Crystal Superalloys for Earth-to-Orbit Propulsion Systems" (Paper presented at the 23rd Joint Propulsion Conference, San Diego, CA, June 29-July 2, 1987, Report NASA TM-89877, Lewis Research Center, Cleveland, $\mathrm{OH}$ ).

2: W.B. McPherson, "A New High Strength Alloy for Hydrogen Fueled Propulsion Systems" (Paper presented at the 22nd Joint Propulsion Conference, Huntsville, Alabama, June 16-18, 1986, Report AIAA-86-1478, AIAA, New York, NY).

3. L.G. Fritzemeier, "The Influence of High Thermal Gradient Casting, Hot Isostatic Pressing and Alternate Heat Treatment on the Structure and Properties of a Single Crystal Nickel Base Superalloy," Superalloys 1988, ed. D.N. Duhl et al. (Warrendale,
PA : The Metallurgical Society, Inc., 1988), 265-274.

4. R.A. Parr, W.S. Alter, M.H. Johnston, and J.P. Strizak, "HighPressure Hydrogen Testing of Single Crystal Superalloys for Advanced Rocket Engine Turbopump Turbine Blades" (Report NASA CP 2372, June 1984), 150-163.

5. R.J. Schwinghamer, "Materials and Processes for Shuttle Engine, External Tank, and Solid Rocket Booster" (Report NASA TN D-8511, George C. Marshall Space Flight Center, Marshall Flight Center, AL, June 1977).

6. H.W. Carpenter, "Alloy 903 Helps Space Shuttle Fly," Metal Progress, August 1976, 25-29.

7. T. Khan and P. Caron, "Advanced Single Crystal Ni-base Superalloys," Advances in High Temperature Structural Materials and Protective Coatings, ed. A. K Koul et al. (Ottawa, Canada : National Research Council of Canada, 1994), 11-31.

8. A.A. Hopgood, and J.W. Martin, "The Effect of Aging on the Yield Stress of a Single-Crystal Superalloy," Mat. Sci. Eng., 91 (1987), 105-110.

9. D. Roux, "Rôle de la microstructure sur la sensibilité à la fragilisation par l'hydrogène de superalliages monocristallins à base de nickel" (Doctoral Thesis, Université Paris-Sud, France, 1993).

10. B. McGurran and J.W. Martin, "'The Control of Slip Distribution by Duplex Dispersions of $\gamma^{\prime}$ Phase in a Nickel-based Superalloy," …Metallkde., 72 (1981), 538-542.

11. P. Mazot, and J. de Fouquet,"Elastic Constant Determination of Nickel Base Superalloy from Room Temperature to $1100^{\circ} \mathrm{C}$ by Dynamical Method,", Mém. et Ét. Sc. Rev. Met., March 1972, 165-170.

12. S.E.P., unpublished work.

13. D.J. Deyes, and W.H. Couts, "Super Waspaloy Microstructure and Properties," MiCon 78 : Optimization of Processing. Properties, and Service Performance Through Microstructural Control.ASTM STP 672, ed. G. N. Maniar et al. (American Society for Testing Material, 1979), 601-615.

14. T. Khan, and P. Caron, "Effect of Processing Conditions and Heat Treatments on Mechanical Properties of Single Crystal Superalloy CMSX-2," Mat. Sc. Technology, 2 (1986), 486-492.

15. S.E.P., unpublished work. 